\title{
Leptodora kindtii population dynamics in the island region of western Lake Erie before and after the invasion of the predacious cladoceran Bythotrephes longimanus
}

\author{
K.E. SIMPSON, Department of Biology, Niagara University, Lewiston, NY, and Department of Environmental, Earth and Ocean \\ Sciences, University of Massachusetts, Boston, MA; W.J. EDWARDS, Department of Biology, Niagara University, Lewiston, NY; \\ and D.D. KANE,' Division of Natural Science, Applies Science and Mathematics, Defiance College, Defiance, OH and F.T. Stone \\ Laboratory, The Ohio State University, Put-In-Bay, OH, USA
}

\begin{abstract}
Competition among native and non-native species can cause decreases in population size and production of both species. The native predaceous crustacean zooplankter Leptodora kindtii shares a similar niche with the invasive Bythotrephes longimanus in Lake Erie. This niche overlap may contribute to the decline in abundance, and production of L. kindtii in the Western Basin of Lake Erie. Historical (1946) and recent (2006) data were used to determine if the decline in L. kindtii abundance and production was associated with the effects of $B$. longimanus, which invaded Lake Erie in the mid-1980's. Pre-invasion abundances and lengths of $L$. kindtii were compared with current data (2006). A change in prey community abundance, composition and dynamics were observed, relative to pre-invasion, with a marked decline in abundance and size of $L$. kindtii after the invasion of $B$. longimanus. Competition for food and direct predation are two explanations, among others, for the declines observed in L. kindtii size, abundance and production that have occurred since $B$. longimanus invasion.
\end{abstract}

Date of Publication: August 2016

OHIO J SCI 116(2): 1-8

\section{INTRODUCTION}

The structure and population dynamics of aquatic communities may by altered by the introduction of non-native, invasive species. Native populations suffer effects including extinction, habitat alteration, and food web disruption, often via changes in energy flow and nutrient availability (Ricciardi and MacIsaac 2000). One disruptive mechanism is interspecific competition between native species and one or more invaders occupying similar niches. However, these interactions are often more complex and the effects are distributed more widely in the food web than simple competition (Strecker and Arnott 2008).

In aquatic ecosystems, zooplankton are functionally important, occupying a mid-trophic level (i.e. primary and secondary consumers) and changes in the ecosystem must propagate through these taxa (Richardson and Schoeman 2004). Changes in phytoplankton composition (i.e. bottom-up effects) are transferred via zooplankton interactions to the

${ }^{1}$ Address correspondence to D.D. Kane, Division of Natural Science, Applies Science and Mathematics, Defiance College, Defiance OH 43512. Email: dkane@defiance.edu fish community (Hampton et al. 2006), while fish community changes, such as loss of predator diversity (i.e. top-down effects), likewise cascade through the secondary producers (Worm et al. 2006). Introduced zooplankton predators act both directly and indirectly on the structure of zooplankton communities and other trophic levels thus, the structure is strongly influenced by predator-prey interactions among trophic levels (Hanazato and Yasuno 1989; Wellborn et al. 1996; Chang and Hanazato 2004; Weis 2011; Weisz and Yan 2011).

Bythotrephes longimanus (Leydig 1860) is a predacious zooplankter native to the Ponto-Caspian region that invaded the Great Lakes during the mid1980s (Lehman 1987). This predator has affected freshwater ecosystems through direct predation and competition with native zooplankton species and through indirect food web alteration (Lehman and Branstrator 1995; Johannsson et al. 1999; Shuter and Mason 2001; Barbiero and Tuchman 2004; Barbiero and Rockwell 2008; Strecker et al. 2011; Yan et al. 2011). Because of similarities in life history, the zooplankter most threatened by $B$. longimanus in the Laurentian Great Lakes is the native predacious cladoceran, Leptodora kindtii (Focke 1844) (Lehman 
and Cáceres 1993). B. longimanus uses similar habitat and is in many ways a superior competitor to L. kindtii (e.g. body size, defense mechanisms, and efficiency of prey consumption) (Berg and Garton 1988; Garton et al. 1990; Branstrator 2005). Other studies have shown the abundance and biomass of $L$. kindtii decreases when the competitor B. longimanus is introduced (Yan et al. 2002). For example, after the initial discovery of B. longimanus in Lake Michigan in 1986, L. kindtii decreased dramatically, along with concurrent decreases and changes in species composition in the Daphnia community (Lehman and Cáceres 1993). These changes in the community remained through 2000 , though attributing this solely to $B$. longimanus is difficult given the wide range of changes in the Lake Michigan ecosystem (Madenjian et al. 2002). Similar declines in L. kindtii and changes in prey composition were observed in Harp Lake, ON (Yan and Pawson 1997) and in Lake Huron (Lehman and Cáceres 1993), where zooplanktivory by B. longimanus outpaces $M y$ sis and fish predation (Bunnell et al. 2011).

In this study we investigate the effects of the introduced predator $B$. longimanus, on the abundance, biomass, and secondary production of the native predator, L. kindtii. We focus on the effects of $B$. longimanus on food web dynamics in the western basin of Lake Erie. We compare historical (pre-invasion, 1946) and recent (post-invasion, 2006) abundance and biomass of $L$. kindtii and compare contemporary estimates of abundance and production of $L$. kindtii and $B$. longimanus. In contrast to other studies, we also assess indirect foodweb effects by comparing seasonal abundance of prey species on a weekly basis. Due to similar niches and the declines in L. kindtii attributed to $B$. longimanus in other lakes, we predicted that L. kindtii abundance, biomass, and secondary productivity would decline in the presence of $B$. longimanus in western Lake Erie.

\section{METHODS}

Zooplankton samples were collected offPeach Point between South Bass Island and Gibraltar Island, in the Western Basin of Lake Erie (Fig. 1). Samples were collected weekly from 22 June to 15 August 2006 one hour after sunset. Predator samples were collected using a horizontal surface $(0-1 \mathrm{~m})$ tow with a $1 \mathrm{~m}$-diameter, $153 \mu \mathrm{m}$-mesh ichthyoplankton net equipped with a flow meter (General Oceanics 2030R), hauled from a motorboat moving at low speed. Surface tows were conducted for predators in order to assure that a large enough volume of water was sampled to collect enough predators to perform necessary length measurements. Prey samples were collected by a vertical tow (surface to near bottom (approximately $8 \mathrm{~m}$ ) and then back to surface) using a 0.5 -meter diameter, $64 \mu \mathrm{m}$-mesh net, equipped with a flow meter (General Oceanics 2030R) until the flow meters indicated approximately $100 \mathrm{~m}^{3}$ of water was sampled. The samples were preserved in sugar formalin (Haney and Hall 1973).

Each prey sample was diluted and enumerated until the most abundant taxa of zooplankton present reached 100 individuals; a minimum of two subsamples were counted for all collections. Cladocerans were identified to species, while copepod copepodites and nauplii were identified to suborder; The densities of each taxon were calculated using flow meter readings. AYSI multiprobe (Yellow Springs Instruments, Yellow Springs, Ohio) was used to measure surface temperature. These samples were representative of Peach Point, where the historical samples of $L$. kindtii were taken. For a comprehensive overview of the changing zooplankton community in Lake Erie and for more details on the general zooplankton sampling and enumeration methods we employed (Conroy et al. 2005, 2008).

Predator samples were diluted and enumerated for abundance and length. We measured the first $20 \mathrm{~L}$. kindtii and $B$. longimanus individual lengths using an ocular micrometer, with the body length of $L$. kindtii from the top of the head to the base of the posterior spine and the body length of $B$. longimanus from the top of the head to the base of the caudal spine (Manca and Comoli 2000). Shrinkage corrections were not applied, as measurements of live individuals were not

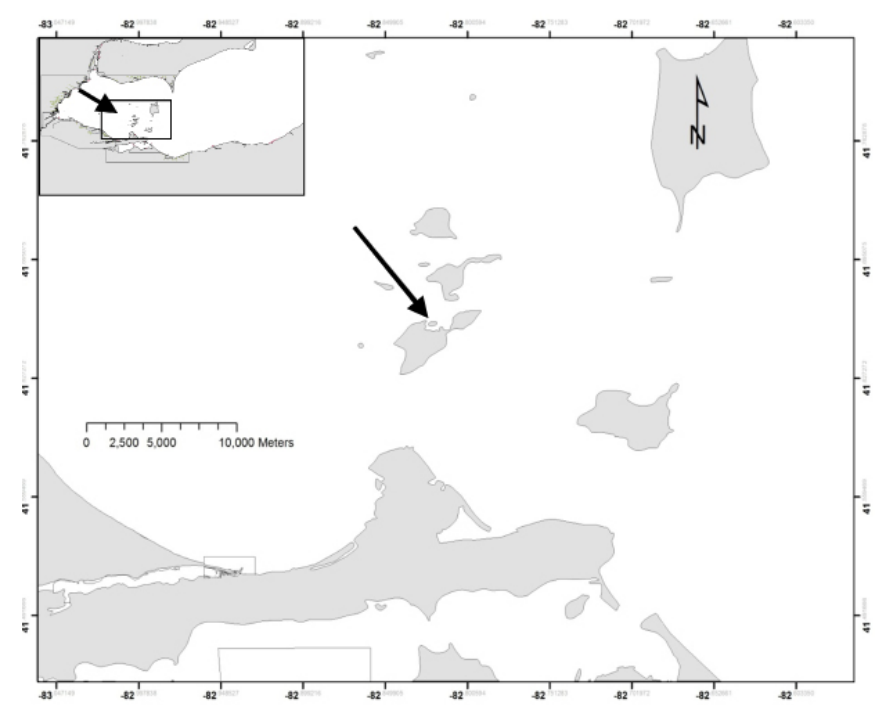

Figure 1. Sampling sites for zooplankton in the Western Basin of Lake Erie during the summer of 2006. 
possible in our sampling regime, which may mean an underestimate of Bythotrephes size in some cases. Individual lengths $(\mathrm{mm})$ were used in a length $(\mathrm{L})$ weight $(\mathrm{W})$ regressions $(\mathrm{W}=\mathrm{aLb})$ and coefficients for L. kindtii $(\mathrm{a}=0.44$, and $\mathrm{b}=2.67)$ and $B$. longimanus $(\mathrm{a}=$ 11.13 and $b=2.77)$ were obtained from Rosen (1981) and Yan (OMEE, Dorset, personal communication 2000) respectively (Johannsson et al. 2000 Appendix 1a) to estimate biomass $\left(B, g / \mathrm{m}^{3}\right)$ for each predatory species. The average biomass of each species for each sampling date was calculated and used in conjunction with known production to biomass ratios $(\mathrm{P} / \mathrm{B})$ in water above $10^{\circ} \mathrm{C}$ (Johannsson et al. 2000) to calculate daily production $(\mathrm{P})$ for each species.

In order to estimate $B$. longimanus consumption of L. kindtii (direct predation upon L. kindtii) and other crustacean zooplankton (competition with $L$. kindtii), we obtained growth efficiency (production/ consumption) estimates for Bythotrephes (Dumitru et al. 2001) and then calculated the consumption rates of L. kindtii required to support the observed production of $B$. longimanus. Growth efficiency of B. longimanus has previously been estimated at 27 percent (Dumitru et al. 2001). Thus the consumption rate must equal 3.7 times the production rate ( 100 percent $/ 27$ percent $)$ to maintain 100 percent production.

Estimates of non-predatory crustacean zooplankton production were made using $\mathrm{P} / \mathrm{B}$ values obtained for non-predatory cladocerans $(0.162)$ at temperatures $>10^{\circ} \mathrm{C}$ (Stockwell and Johannsson 1997 (as cited in Johannsson et al. 2000)) and for cyclopoids (0.169) and calanoids (0.060) using a median water temperature of $24.7^{\circ} \mathrm{C}$ [Shuter and Ing 1997 (as cited in Johannsson et al. 2000)]. Because we could not have actual production values for our non-predatory crustacean zooplankton (due to lack of length measurements taken), we obtained a range of $50-250 \mathrm{ug} / \mathrm{L}\left(\mathrm{mg} / \mathrm{m}^{3}\right)$ for the crustacean biomass of in western Lake Erie during June-August (1995-2003) from the literature (Conroy et al. 2008). We then calculated an average biomass value for non-predatory cladocerans, cyclopoids, and calanoids and then multiplied this value by the $\mathrm{P} / \mathrm{B}$ ratio to obtain a range of production values for nonpredatory crustacean zooplankton.

\section{RESULTS}

Herbivorous zooplankton abundance (cladocerans and copepods) declined from 29 June 2006 to 15 August 2006 at our sample site (Fig. 2). Cladoceran abundances exhibited two peaks with the first of the two consisting of primarily Daphnia retrocurva and Bosmina and the second Eubosmina and Diaphanasoma (Fig. 2a). The peak abundance in copepods occurred from 22 June to 28 June and was composed primarily of cyclopoid copepodites. From 28 June to 7 July abundance declined sharply, with cyclopoid copepodites remaining the most abundant taxa (Fig. 2b). From 3 August until 9 August, calanoid copepodites continued to increase while the other three groups declined, causing a shift to calanoid copepods as the most abundant taxon by the end of the sampling period.

L. kindtii densities reached a seasonal peak on 19 July followed by a steady decline until 9 August. There was a slight increase on the last sample date, perhaps corresponding to the beginning of a seasonal increase (Fig. 3). The average density of $L$. kindtii throughout the summer was 234.9 individuals $/ \mathrm{m}^{3}$, ranging from 39.9 individuals $/ \mathrm{m}^{3}$ on 7 July to 560.1 on 19 July. $B$. longimanus was not present in samples before 26 July.
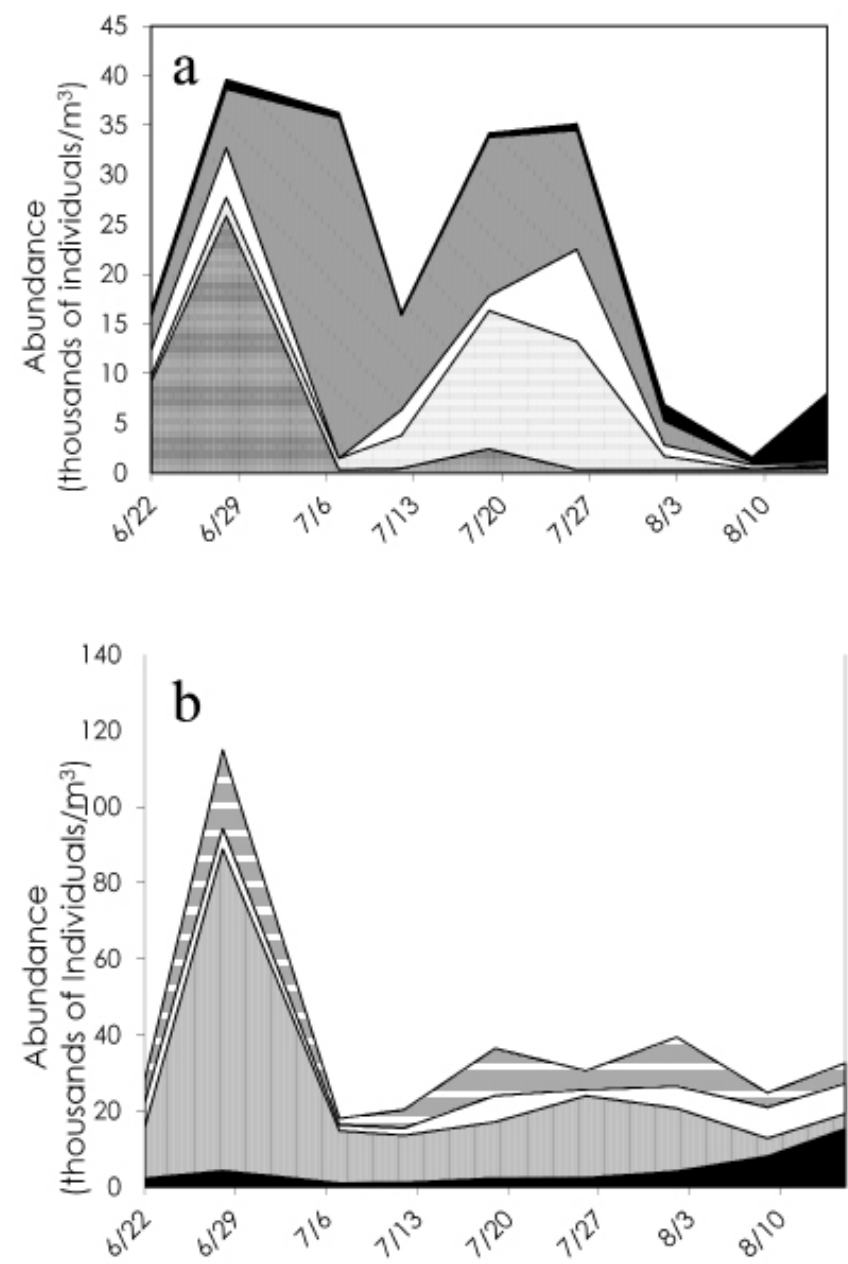

Figure 2.a.) Cladoceran seasonal abundances in the western basin of Lake Erie during the summer of 2006: Daphniagaleatamendotae M Daphnia retrocurva $\square$ Diaphanasoma Eubosmina

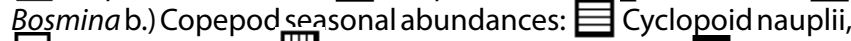
$\square$ Calanoid nauplii, $\mathbf{W}$ Cyclopoid copepodites, and $\square$ Calanoid copepodites. 
From this date, $B$. longimanus abundance increased throughout the remainder of the sampling period (Fig. 3). The density of $B$. longimanus ranged from 3.27 individuals $/ \mathrm{m}^{3}$ on 26 July to 34.1 individuals/ $\mathrm{m}^{3}$ on 15 August. There was a concomitant decline in L. kindtii density and this pattern continued for the next three sampling events (Fig. 3). However, on the final sample date (15 August) there was an increase in $L$. kindtii though $B$. longimanus was at relative peak abundance. Water temperatures varied slightly with a lower initial temperature of $23^{\circ} \mathrm{C}$ and peak water temperature of $27^{\circ} \mathrm{C}$ on 21 July.

The average length of $L$. kindtii from 22 June to 12 July remained relatively constant and then became more variable (Fig. 4a). The average length of all $L$. kindtii measured was $3.67+/-0.37 \mathrm{~mm}$ and these individuals ranged from $0.6 \mathrm{~mm}$ to $8.25 \mathrm{~mm}$. $B$. longimanus length ranged from $0.98 \mathrm{~mm}$ to $2.7 \mathrm{~mm}$, and the mean was $1.70 \mathrm{~mm}$. The population biomass of L. kindtii remained constant through 7 July between 2 to $4 \mathrm{~g} / \mathrm{m}^{3}$. Peak population biomass was measured on 26 July corresponding to both peak abundance and peak measured lengths. A sharp decrease followed from 26 July to 9 August, and then a slight increase in biomass was observed from 9 August to 15 August (Fig. $4 \mathrm{~b})$. B. longimanus showed a sharp increase in biomass which corresponded with the L. kindtii decline (Fig. $4 \mathrm{~b})$. The maximum production found throughout the sampling period for $L$. kindtii was $6.92 \mathrm{~g} / \mathrm{m}^{3} /$ day on 26 July, and the minimum was found to be $0.058 \mathrm{~g} /$ $\mathrm{m}^{3} /$ day on 9 August (Fig.4c). The production of $B$. longimanus ranged from $0.059 \mathrm{~g} / \mathrm{m}^{3} /$ day on the date of initial appearance to $0.628 \mathrm{~g} / \mathrm{m}^{3} /$ day on the last date

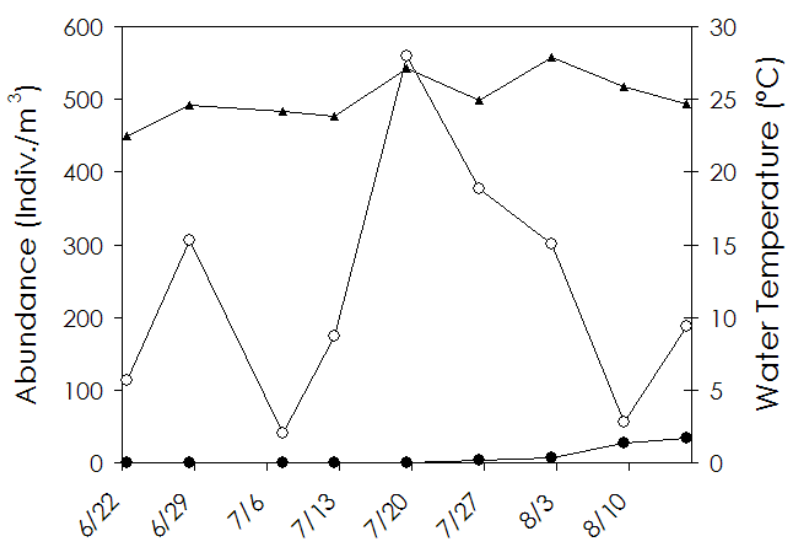

Figure 3. The abundance of Bythotrephes longimanus - and Leptodora kindtii $-\mathrm{O}$ in relation to temperature - in the western basin of Lake Erie during the summer of 2006. in the sample period (Fig.4c). A significant decline in production of $L$. kindtii occurred simultaneously with the appearance of $B$. longimanus.

Data from Andrews (1948) were compared with current data to determine if the abundance of $L$. kindtii has declined since the invasion of $B$. longimanus. Andrews published data including abundance and lengths of parthenogenetically produced females of $L$. kindtii from Hatchery Bay (near the same sample site as this study), starting on 16 June 1946 and ending on 25 October 1946. The nightly abundances of L. kindtii from mid-June 1946 to early to mid-July 1946 were high compared to the abundance from later dates within that same summer (Fig. 4d). The maximum abundance of $L$. kindtii during the summer of 1946 occurred on 2 July with a density of 8,274 individuals $/ \mathrm{m}^{3}$. The average density from 18 June to 12 July (the time of the highest abundance) was 2,808 individuals $/ \mathrm{m}^{3}$. During the latter part of the summer (15 July to 30 August) the average density decreased to 425 individuals $/ \mathrm{m}^{3}$. In contrast, the greatest numbers found in 2006 were $<600$ individuals $/ \mathrm{m}^{3}$. In addition, the average length of $L$. kindtii $(\mathrm{n}=830)$ found during the summer also declined by approximately half, from $7.69 \mathrm{~mm}$ (1946) to $3.67 \mathrm{~mm}$ (2006). There was also a broader distribution of individual lengths in 1946 than in 2006 (Fig. 5).

By applying consumption rates of 3.7 times production rate (see above) to the production levels of $B$. longimanus we obtained consumption values ranging 0.22 to $2.95 \mathrm{~g} / \mathrm{m}^{3} / \mathrm{d}$ (when B. longimanus was present). Comparing this with $L$. kindtii productivities ranging from 0.06 to $6.92 \mathrm{~g} / \mathrm{m}^{3} / \mathrm{d}$ (Fig. 4c) indicates that on the two later dates in 2006 (9 August and 15 August) that $B$. longimanus is present it could potentially prey on all L. kindtii, while on the other two dates (26 July and 2 August) it could not.

Average $\mathrm{P} / \mathrm{B}$ ratio for non-predatory crustaceans was calculated to be $0.345 / \mathrm{d}$ ((cladoceran $=0.145$, cyclopoid $=0.654$, calanoid $=0.231)$ ). Multiplying this by $50-250 \mathrm{mg} / \mathrm{m}^{3}$ yields an estimate of $0.0173-0.0865$ $\mathrm{g} / \mathrm{m}^{3} / \mathrm{d}$ of non-predatory crustacean zooplankton production. Based on consumption values of 0.22 to $2.95 \mathrm{~g} / \mathrm{m}^{3} / \mathrm{d}$, Bythotrephes could theoretically consume all of this non-predatory crustacean production during the Bythotrephes one week production maximum at this sample site. However, given the relatively low abundance during the rest of the growing season, these impacts would be limited to the peak $B$. longimanus production. 


\section{DISCUSSION}

L. kindtii abundance was lower in 2006 than 1946, and corresponding differences in potential predator consumption rates and observed prey community structure suggest that $B$. longimanus influenced the change. When $L$. kindtii and B. longimanus co-exist, both competition for resources and direct predation of $L$. kindtii by $B$. longimanus may contribute to decreased abundance of the native $L$. kindtii. During the summer of 2006, we observed a decrease in L. kindtii abundance, biomass and productivity that inversely correlated with B. longimanus. By comparison in 1946, L. kindtii abundance increased through August. Yan and Pawson (1997) found similar effects on the $L$. kindtii population in the smaller Harp Lake (Ontario, Canada). They attribute this to direct predation by B. longimanus on L. kindtii. Further, Barbiero and Tuchman (2004) suggested that declines in L. kindtii in lakes Michigan, Huron, and Erie (Central and Eastern basins) after introduction of $B$. longimanus were due to direct predation and not competition
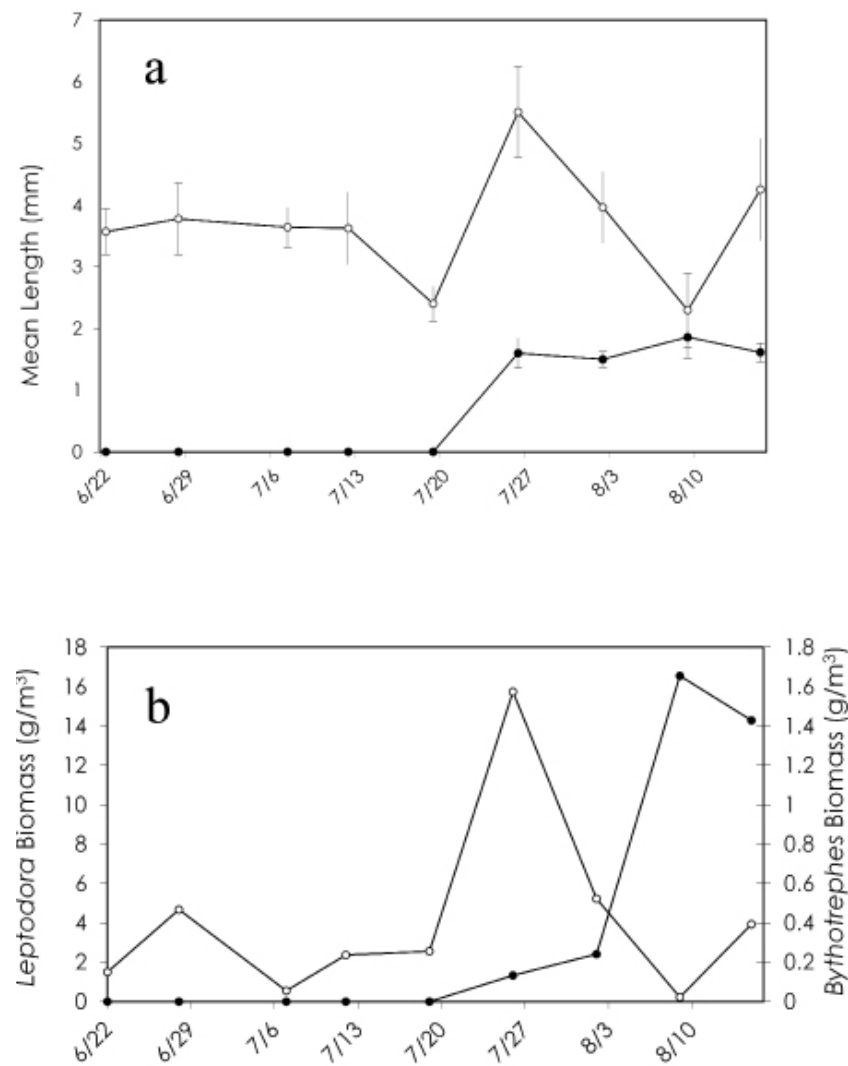

owing to increases of $L$. kindtiis preferred rotifer prey in those lakes. However, we also saw concomitant changes in prey structure, which has been linked to B. longimanus introductions in other lakes (Hovius et al. 2006; Manca et al. 2008) as well as introductions of the similar Cercopagis pengoi (Warner et al. 2006).

Similar to these other studies, prey structure changes at our site were consistent with competition effects of $L$. kindtii and B. longimanus, but long-term environmental changes between 1946 and 2006 also may have restructured the prey community via bottom-up trophic and/or abiotic effects. For example, the combination of competition, predation, and temperature are important in structuring predaceous cladoceran dynamics in Lake Michigan (Cavaletto et al. 2010). B. longimanus has different life history strategies than its competitor as noted by Branstrator (2005). This comparative study in life histories noted that the caudal spine protection of B. longimanus
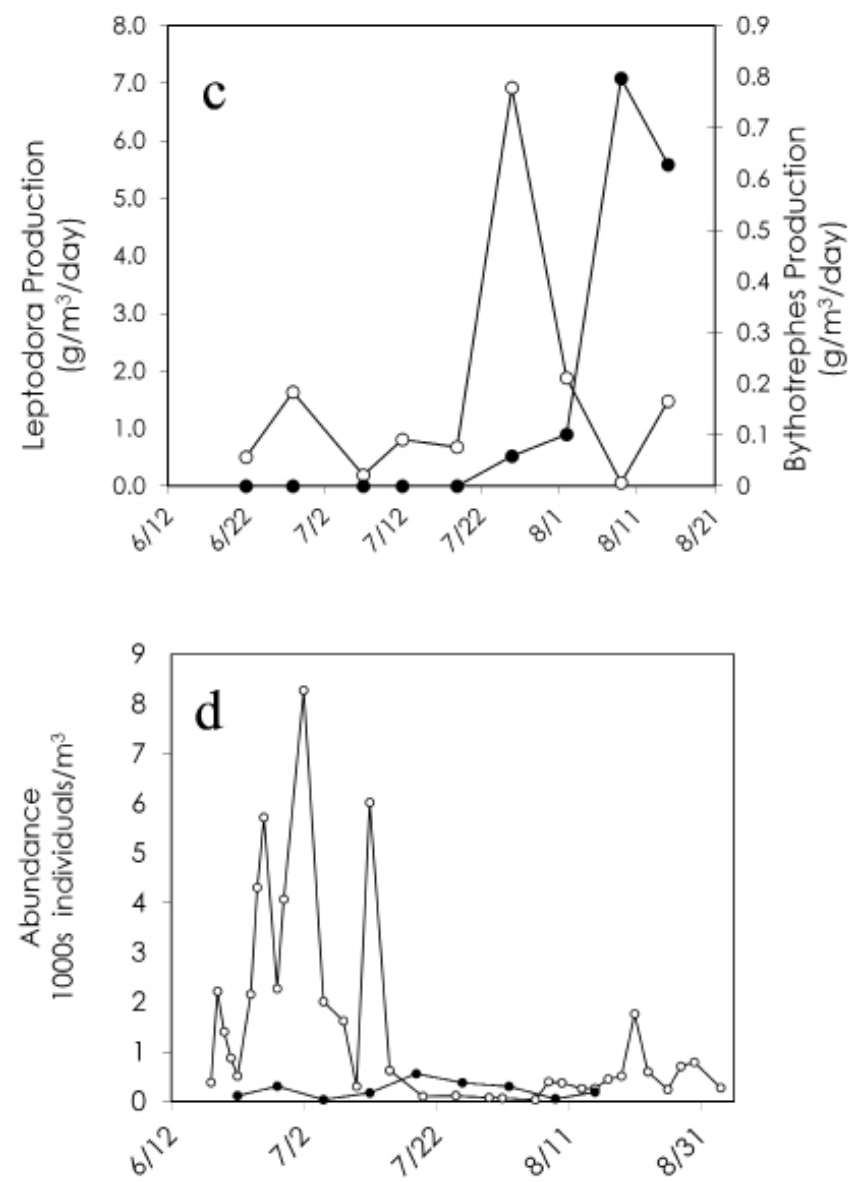

Figure 4. a.) The mean lengths (+/- SE) in millimeters of Leptodora kindtii (open circles-O-) and B. longimanus (closed circles-0-) throughout the summer of 2006 in the western basin of Lake Erie. b.) The mean population biomass $\left(\mathrm{g} / \mathrm{m}^{3}\right.$ ) in for each predator species found in the western basin of Lake Erie during the summer of 2006. Leptodora kindtii (open circles-O-) corresponds to the left $y$-axis and B. longimanus (closed circles - - corresponds to the right y-axis. c.) The daily production ( $\mathrm{g} / \mathrm{m}^{3} /$ day) of Leptodora kindtii and Bvthotrephes longimanus in the western basin of Lake Erie during the summer of 2006. L. kindtii production is indicated by the open circles $-O-$ and corresponds to the left $y$-axis values, and $B$. longimanus is in closed circles - corresponding to the right $y$-axis values. $d$.) $A$ comparison of $L$. kindtii abundances during the summer of 1946 (open circles-O-) and the summer of 2006 (closed circles - -) in the western basin of Lake Erie. 
provides additional post-contact protection against predation, lacking in L. kindtii. Further, Yan and Pawson (1997) found that egg production in L. kindtii did not always decrease in response to increasing $B$. longimanus production, supporting a role for selective fish predation on L. kindtii.

The abundance of $L$. kindtii in western Lake Erie declined between 1946 and 2006. Abundances published by Andrews (1948) for the summer of 1946 showed only peaks occurred early in the season, followed by a decline in abundances. These peaks were not evident in data collected from the summer of 2006. For the remainder of both summers, $L$. kindtii showed little differences in abundance. In addition, data published soon after the invasion of $B$. longimanus by Berg and Garton (1988) did not show these historical peaks in L. kindtii abundance early in the summer of 1987.

Hubschman (1960) published daily population densities of cladocerans from the Bass Island region of Lake Erie for the summer of 1959. Several species of cladocerans showed a different trend in the summer of 1959 than in 2006. In 1959, total daily population densities of cladocerans (other than L. kindtii) showed several peaks though out the entire summer (30 June to 21 August) (Hubschman 1960) while in 2006, the only peak occurred early in the season, followed by a decline in total species. Barbiero and Tuchman (2004) provide evidence that alterations in zooplankton communities occurred in lakes Michigan, Huron, and Erie (Central and Eastern basins) after introduction of $B$. longimanus, including alteration of Daphnia and other cladoceran yearly abundances. Perhaps less food in the way of non-predatory cladocerans is now

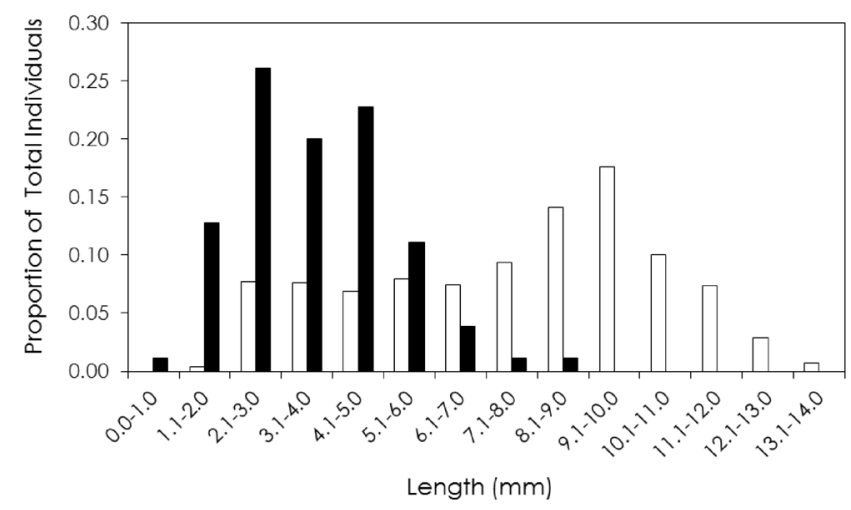

Figure 5. A histogram comparing Leptodora kindtii lengths from the summer of 1946 (Andrews, 1948) (white bars) and the summer of 2006 (black bars) within the Western Basin of Lake Erie. The proportions of individuals in each length $(\mathrm{mm})$ size class are given. available later in the summer and this may limit $L$. kindtii population size.

Previous studies suggest that $B$. longimanus invasion caused declines in $L$. kindtii abdundance in North America (Foster and Sprules 2009, Weisz and Yan 2011), as well as a trend for smaller $L$. kindtii size with increased abundances of invasive $B$. longimanus (Foster et al. 2012). Foster et al. (2012) suggest size declines in $L$ kindtii in central Ontario lakes invaded by $B$. longimanus could be due to direct consumption by $B$. longimanus, indirect effects of $B$. longimanus decreasing available zooplankton prey for $L$. kindtii, and other factors, such as fish predation. They concluded that decreased $L$. kindtii size was due to competitive effects of $B$. longimanus predation on small cladocerans. While our study shows a decline in $L$. kindtii abundance and size correlated with the invasion of $B$. longimanus, we cannot easily attribute the cause entirely to competitive or predatory interactions.

The Lake Erie ecosystem has undergone many changes since the 1940s, including fluctuations in nutrient loading, algal blooms, and regional climate change. Eutrophication, and the water quality issues associated with it including Central Basin hypoxia and harmful algal blooms (HABs), led to the implementation of the Great Lakes Water Quality Agreement. One result of the agreement is seen in reductions of total phosphorus (TP) in the water column and a subsequent reduction in hypolimnetic oxygen depletion rate the early 1970s until the early 1990s (Bertram 1993). By the mid-1990s there was an increase in mesotrophic plankton species (Munawar et al. 2002; Kane et al. 2004). However, recently, phytoplanktonic communities have shown a resurgence of eutrophic taxa and increased biomass of inedible/ potentially toxic cyanobacterial taxa (Conroy et al. 2008; Kane et al. 2014) at the same time that SRP concentrations in the water column are rebounding (Baker et al. 2014, Kane et al. 2014)), though there has been no rebound in $L$. kindtii. These changes are concurrent with the introduction of $B$. longimanus and may also have contributed to the decline of L. kindtii size, abundance, and production.

\section{ACKNOWLEDGMENTS}

We thank Drs. Michael Kotarski and Deborah Leonard at Niagara University (NU) and Dr. Michael Blum at Tulane University for reviewing earlier versions of this manuscript. We appreciate the support of the NUAcademic Center for Integrated Sciences. We thank 
the staff at F.T. Stone Laboratory (Put-In-Bay, Ohio) for the use of their equipment and facilities, and in particular the help of Matt Thomas. A Stone Laboratory Visiting Scientist grant to D.D.Kane provided funding for this study's field work. We thank several anonymous reviewers for their helpful suggestions that improved this manuscript.

\section{LITERATURE CITED}

Andrews TF. 1948. The life history, distribution, growth, and abundance of Leptodora kindtii (Focke) in western Lake Erie [dissertation]. [Columbus, $\mathrm{OH}$ ]: The Ohio State University

Barbiero RP, Tuchman ML. 2004. Changes in the crustacean communities of Lakes Michigan, Huron, and Erie following the invasion of the predatory cladoceran, Bythotrephes longiminus. Can. J. Fish. Aquat. Sci. 61:2111-2125.

Barbiero RP, Rockwell DC. 2008. Changes in the crustacean communities of the central basin of Lake Erie during the first full year of the Bythotrephes longimanus invasion. J. Great Lakes Res. 34:109-121. doi: 10.3394/0380-1330(2008)34\%5B10 9:CITCCO\%5D2.0.CO;2.

Baker DB, Confesor R, Ewing DE, Johnson LT, Kramer JW, Merryfield, BJ. 2014. Phosphorus loading to Lake Erie from the Maumee, Sandusky and Cuyahoga rivers: the importance of bioavailability. J. Great Lakes Res. 40:502-517. doi: 10.1016/j.jglr.2014.05.001.

Berg DJ, Garton DW. 1988. Seasonal abundance of the exotic predatory cladoceran Bythotrephes cederstroemi in western Lake Erie. J. Great Lakes Res. 14:479-488. doi: 10.1016/ S0380-1330(88)71580-4.

Bertram P. 1993. Total phosphorus and dissolved oxygen trends in the central basin of Lake Erie. J. Great Lakes Res. 19:224-236.

Branstrator DK. 2005. Contrasting life histories of the predatory cladocerans Leptodora kindtii and Bythotrephes longiminus. J. Plankton Res. 27:569-585.

Bunnell D B, Davis BM, Warner DM, Chriscinske MA, Roseman EF. 2011. Planktivory in the changing Lake Huron zooplankton community: Bythotrephes consumption exceeds that of Mysis and fish. Freshwater Biol. 56:1281-1296. doi: 0.1111/j.1365-2427.2010.02568.x.

Cavaletto JF, Vanderploeg HA, Piclová-Ptáčníková R, Pothovern SA, Liebig JR, Fahnenstiel GL. 2010. Temporal and spatial separation allow coexistence of predatory cladocerans: Leptodora kindtii, Bythotrephes longimanus, and Cercopagis pengoi, in southeastern Lake Michigan. J. Great Lakes Res. 36:65-73. doi: 0.1016/j.jglr.2010.04.006.

Chang K, Hanazato T. 2004. Predation impact of Leptodora kindtii on population dynamics and morphology of Bosmina fatalis and B. longirostris in mesocosms. Freshwater Bio. 49:253-264. doi: 10.1111/j.1365-2427.2004.01181.x.

Conroy JD, Kane DD, Dolan DM, Edwards WJ, Charlton, MN, Culver, DA. 2005. Temporal trends in Lake Erie plankton biomass: roles of external phosphorus loading and dreissenid mussels. J. Great Lakes Res. 31:89-110. doi: 10.1016/S03801330(05)70307-5.

Conroy JD, Kane DD, Culver DA. 2008. Declining Lake Erie ecosystem health? Evidence from a multi-year, lake-wide, plankton study. Pages 369-408. In: Munawar M, Heath, R, editors. Checking the pulse of Lake Erie (Ecovision World Monograph). New Delhi, India: Goodword Books. doi: 10.1016/S0380-1330(05)70307-5.
Dumitru C, Sprules WG, Yan ND. 2001. Impact of Bythotrephes longimanus on zooplankton assemblages of Harp Lake, Canada: an assessment based on predator consumption and prey production. Freshwater Biol. 46:241-251. doi: 10.1046/j.1365-2427.2001.00649.x.

Foster SE, Sprules WG. 2009. Effects of the Bythotrephes invasion on native predatory invertebrates. Limnol. Oceanogr. 54:757769. doi: 10.4319/lo.2009.54.3.0757.

Foster SE, Sprules WG, Strecker AL. 2012. Effects of Bythotrephes longimanus (Crustacea, Cladocera) on the abundance, morphology, and prey community of Leptodora kindtii (Crustacea, Cladocera). Hydrobiol. 683:163-172. doi: 10.1007/s10750-011-0953-4.

Garton DW, Berg DJ, Fletcher RJ. 1990. Thermal tolerances of the predatory cladocerans Bythotrephes cederstroemi and Leptodora kindtii: relationship to seasonal abundance in western Lake Erie. Can. J. Fish Aquat. Sci. 47:731-738.

Hampton SE, Scheuerell MD, Schindler DE. 2006. Coalescence in the Lake Washington story: Interaction strengths in a planktonic food web. Limnol. Oceanog. 51:2042-2051. doi: 10.4319/lo.2006.51.5.2042.

Hanazato T, Yasuno M. 1989. Zooplankton community structure driven by vertebrate and invertebrate predators. Oecologia 81:450-458. doi: 10.1007/BF00378951.

Haney JF, Hall DJ. 1973. Sugar-coated Daphnia: a preservation technique for Cladocera. Limnol. Oceanog. 18:331-333.

Hovius JT, Beisner BE, McCann KS. 2006. Epillimnetic rotifer community responses to Bythotrephes longimanus invasion in Canadian Shield lakes. Limnol. Oceanog. 51:1004-1012.

Hubschman JH. 1960. Relative daily abundance of planktonic Crustacea in the island region of western Lake Erie. Ohio J. Sci. 60:335-340.

Johannsson OE, Graham DM, Einhouse DWE, Mills EL. 1999. Historical and recent changes in the Lake Erie zooplankton community and their relationship to ecosystem function. In Munawar, M, Edsall, T, and Munawar, IF, editors, State of Lake Erie-past, present and future.Leiden (The Netherlands): Backhuys. p. 169-196.

Johannsson OE, Dermott R, Graham DM, Dahl JA, Millard S, Myles DD, LeBlanc J. 2000. Benthic and pelagic secondary production in Lake Erie after the invasion of Dressiena spp. with implications for fish production. J. Great Lakes Res. 26:31-54.

Kane DD, Conroy JD, Richards RP, Baker DB, Culver DA. 2014. Re-eutrophication of Lake Erie: correlation of tributary nutrient loads and phytoplankton biomass. J. Great Lakes Res. 40:496-501. doi: 10.1016/j.jglr.2014.04.004.

Kane DD, Gannon JE, Culver DA. 2004. The status of Limnocalanus macrurus (Copepoda: Calanoida: Centropagidae) in Lake Erie. J. Great Lakes Res. 30:22-30. doi: 10.1016/S0380-1330(04)70326-3.

Lehman JT. 1987. Palearctic predator invades North American Great Lakes. Oceologia 74:478-480. doi: 10.1007/ BF00378947.

Lehman JT, Branstrator,DK. 1995. A model for growth, development and diet selection by the invertebrate predator Bythotrephes cederstroemi. J. Great Lakes Res. 21:610-619. doi: 10.1016/S0380-1330(95)71072-3.

Lehman JT, Cáceres CE. 1993. Food-web responses to species invasion by a predatory invertebrate: Bythotrephes in Lake Michigan. Limnol. Oceanog. 38:879-891. 
Madenjian CP, Fahnenstiel GL, Johengen TH, Nalepa TF, Vanderploeg HA, Fleischer GW, Schneeberger PJ, Benjamin DM, Smith EB, Bence JR, Rutherford ES, Lavis DS, Robertson DM, Jude DJ, Ebener, MP. 2002 Dynamics of the Lake Michigan food web, 1970-2000. Can. J. Fish. Aquat. Sci. 59:736-753. doi: 10.1139/f02-044.

Manca M, Comoli P. 2000. Biomass estimates of freshwater zooplankton from length-carbon regression equations. J. Limnol. 59:15-18. doi: 10.4081/jlimnol.2000.15.

Manca M, Vijverberg J, Polishchuk LV, Voronov DA. 2008. Daphnia body size and population dynamics under predation by invertebrate and fish predators in Lago Maggiore: an approach based on contribution analysis. J. Limnol. 67:1521. doi: 10.4081/jlimnol.2008.15.

Munawar M, Munawar IF, Dermott R, Niblock H, Carou S. 2002. Is Lake Erie a resilient ecosystem? Aquat. Ecosyst. Health Manage. 5:79-93. doi: 10.1080/14634980260199981.

Ricciardi A, MacIsaac HJ. 2000. Recent invasion of the North American Great Lakes by Ponto-Caspian Species. Trends Ecol. Evol. 15:62-65. doi: 10.1016/S0169-5347(99)01745-0.

Richardson AJ, Schoeman DS. 2004. Climate impact on plankton ecosystems in the Northeast Atlantic. Science 305:1609-1612. doi: $10.1126 /$ science. 1100958 .

Rosen RA. 1981. Length-dry weight relationships of some freshwater zooplankton. J. Freshwater Ecol. 21:225-229.

Shuter BJ, Ing KK. 1997. Factors affecting the production of zooplankton in lakes. Can. J. Fish. Aquat. Sci. 54:359-377. doi: 10.1139/f96-270.

Shuter BJ, Mason DM. 2001. Exotic invertebrates, food-web disruption, and lost fish production: understanding impacts of dreissenid and cladoceran invaders on lower-lakes fish communities and forecasting invasion impacts on upper-lakes fish communities. Ann Arbor, Michigan: Board of Technical Experts, Great Lakes Fishery Commission.

Stockwell JD, Johannsson OE. 1997. Temperature-dependent allometric models to estimate zooplankton production in temperate freshwater lakes. Can. J. Fish. Aquat. Sci. 54:23502360. doi: 10.1139/f97-141.
Strecker AL, Arnott SE. 2008. Invasive predator, Bythotrephes, has varied effects on ecosystem function in freshwater lakes. Ecosystems 11:490-503. doi: 10.1007/s10021-008-9137-0.

Strecker AL, Beisner BE, Arnott SE, Paterson AM, Winter JG, Johannsson OE, Yan NE. 2011. Direct and indirect effects of an invasive planktonic predator on pelagic food webs. Limnol. Oceanog. 56:179-182. doi: 10.4319/lo.2011.56.1.0179.

Warner D, Rudstam LG, Hugues B, Mills EL, Johannsson O. 2006. Changes in seasonal nearshore zooplankton abundance patterns in Lake Ontario following establishment of the exotic predator Cercopagis pengoi. J. Great Lakes Res. 32:531-542.

Weis JS. 2011. Invasion and predation in aquatic ecosystems. Curr. Zool. 57:613-624. doi: 10.3394/0380-1330(2006)32\%5B5 31:CISNZA\%5D2.0.CO;2.

Weisz EJ, Yan ND. 2011. Shifting invertebrate zooplanktivores: watershed-level replacement of the native Leptodora by the non-indigenous Bythotrephes in Canadian Shield lakes. Biol. Invasions 13:115-123. doi: 10.1007/s10530-010-9794-8.

Wellborn GA, Skelly DK, Werner EE. 1996. Mechanisms creating community structure across a freshwater habitat gradient. Ann. Rev. Ecol. System. 27:337-363.

Worm B, Barbier EB, Beaumont N, Duffy JE, Folke C, Halpern BS, Jackson JBC, Lotze HK, Micheli F, Palumbi SR, Sala E, Selkoe KA, Stachowicz JJ, Watson R. 2006. Impact of biodiversity loss on ocean ecosystem services. Science 314:787790. doi: $10.1126 /$ science. 1132294 .

Yan ND, Pawson TW. 1997. Changes in the crustacean community of Harp Lake, Canada, following invasion by Bythotrephes cederstroemi. Freshwater Biol. 37:409-425. doi: 10.1046/j.1365-2427.1997.00172.x.

Yan ND, Girard R, Boudreau S. 2002. An introduced invertebrate predator (Bythotrephes) reduces zooplankton species richness. Ecology Letters 5:481-485. doi: 10.1046/j.14610248.2002.00348.x.

Yan, ND, Leung, B, Lewis MA, Peacor, SD. 2011. The spread, establishment and impacts of the spiny water flea, Bythotrephes longimanus, in temperate North America: a synopsis of the special issue. Biol. Invasions 13:2423-2432. doi: 10.1007/ s10530-011-0069-9. 